\title{
Exposure of BALB/c mice to low doses of Mycobacterium avium increases resistance to a subsequent high-dose infection
}

\author{
Lanfranco Fattorini, Roberto Nisini, Yuming Fan, Yong-Jun Li, \\ Dejiang Tan, Sabrina Mariotti, Raffaela Teloni, Elisabetta Iona \\ and Graziella Orefici
}

Author for correspondence: Dr Graziella Orefici. Tel: +3906 49902333. Fax: + 390649387112.
e-mail: gorefici@iss.it

Laboratory of Bacteriology and Medical Mycology, Istituto Superiore di Sanità, Viale Regina Elena 299, 00161 Rome, Italy

\begin{abstract}
BALB/c mice exposed intranasally (i.n.), intradermally (i.d.) or intraperitoneally (i.p.) to low doses of Mycobacterium avium (20 c.f.u. at three different times two weeks apart) showed an increased resistance to a subsequent high-dose $\left(10^{5}\right.$ c.f.u.) infection. I.n.-exposed mice had few mycobacteria in the tissues ( $\leq 100$ c.f.u.) and showed an expansion of $\mathrm{CD}^{+} \mathrm{T}$ cells associated with overproduction of IL-12 and IFN- $\gamma$, but not IL-4 and IgG antibodies. Parenterally (i.p. and i.d.) exposed animals showed c.f.u. numbers higher than i.n.-exposed mice, together with overproduction of IL-12, IFN- $\gamma$ and IL-4 in the case of i.p.exposed mice, and of IL-12, IFN- $\gamma$ and IgG2a and IgG1 antibodies in the case of i.d.-exposed mice. Low-dose exposures were not contained by athymic BALB/c nude mice; however, naive nude mice reconstituted with i.n.-primed CD4+ $T$ cells of BALB/c mice were protected against high-dose infection, indicating that $\mathrm{CD4}^{+} \mathrm{T}$ cells are essential to control even low-dose infections by $M$. avium. Overall, these data suggest that continuous i.n. exposure to $M$. avium doses commonly found in the environment may play a role in determining the natural resistance of normal hosts against this organism.
\end{abstract}

Keywords: intranasal low-dose exposure, intradermal low-dose exposure, intraperitoneal low-dose exposure, $\mathrm{BALB} / \mathrm{c}$ nude mice, $\mathrm{CD} 4^{+} \mathrm{T}$ cells

\section{INTRODUCTION}

Organisms belonging to the Mycobacterium avium complex have been isolated from animals, dust, soil, food, cigarettes and, in particular, water sources (piped water supply systems and environmental sites), where they can reach concentrations up to 1000 c.f.u. $\mathrm{ml}^{-1}$ (von Reyn et al., 1993; Eaton et al., 1995; Horshburgh, 1996; Falkinham, 1996; Falkinham et al., 2001). While humans are highly susceptible to Mycobacterium tuberculosis, $M$. avium infections are usually rare, with the exception of pulmonary diseases, lymphadenitis in children, or disseminated infections in $\mathrm{HIV}^{+}$patients with low CD4 ${ }^{+} \mathrm{T}$ cell counts (Inderlied et al., 1993). Infection by $M$. avium is thought to occur as a result of the colonization of the respiratory and gastrointestinal tracts by aerosols generated by showers and natural waters (Inderlied et al., 1993; Falkinham, 1996). Skin

Abbreviations: i.d., intradermal(ly); i.n., intranasal(ly); i.p., intraperitoneal(ly). test positivity is much more frequent than clinical $M$. avium disease (Horshburgh, 1996), indicating a widespread subclinical infection by this organism that may be responsible for the resistance state of healthy individuals.

Many of the studies on the interaction of M. avium with the host have been done by infecting mice with doses of mycobacteria ranging from $10^{6}$ to $10^{8}$ c.f.u. (Appelberg et al., 1995; Corti et al., 1999; Kobayashi et al., 1995; Saunders et al., 1995). However, these approaches do not reflect the immune response generated by the natural exposure to the infection, where small bacterial loads may infect the host by different routes including, for instance, water aerosols and skin lesions (Falkinham, 1996; Horshburgh, 1996; Noguchi et al., 1998; Smith \& Grange, 1989).

While most of the studies investigating the host reaction to small doses of mycobacteria have been performed with Mycobacterium bovis (Chambers et al., 2001), M. bovis BCG (Power et al., 1998; Bretscher et al., 2001) 
and M. tuberculosis (Brown et al., 1995; Cooper et al., 1995), only a few reports have focused on M. avium (Saunders et al., 1998). The purpose of the present study was to mimic the natural exposure to low M. avium doses in immunocompetent BALB/c or athymic BALB/c nude mice in order to evaluate the possible elicitation of an acquired resistance state and immune response. The results obtained seem to indicate that the low-dose infection caused by intranasal exposure of immunocompetent mice to a few $M$. avium bacteria induces a longlasting resistance to a subsequent challenge with the same micro-organism.

\section{METHODS}

Micro-organism. A clinical isolate of Mycobacterium avium obtained from an AIDS patient (strain 485, virulent transparent colonies) was used throughout the study (Fattorini et al., 1996). Colonies grown on Middlebrook 7H10 agar plates (Difco) were suspended in PBS and sonicated for $10 \mathrm{~s}$ to disperse clumps. Suspensions were adjusted to an $\mathrm{OD}_{500}$ of $0 \cdot 2$ (corresponding to approximately $6 \times 10^{8}$ c.f.u. $\mathrm{ml}^{-1}$ ) and used to inoculate the mice.

Design of the study. Male BALB/c or athymic $n u / n u$ BALB/c (nude) mice aged 5 to 7 weeks were obtained from Charles River. BALB/c mice were bred and maintained under standard conditions, receiving sterilized chow and water ad libitum. Nude mice were housed in pathogen-free conditions in a flexible-film isolator equipped with a negative-pressure HEPAfiltered air system.

Mice were exposed to $20 \mathrm{M}$. avium c.f.u. administered intranasally (i.n.), intradermally (i.d.) or intraperitoneally (i.p.) at three different times 2 weeks apart (days 0, 14 and 28). Inocula consisted of $40 \mu \mathrm{l}$ for i.n. exposure $(20 \mu \mathrm{l}$ per nostril, using a Gilson micropipette), $50 \mu$ l for i.d. exposure (injected in the epidermis of the sternal region, using a Hamilton syringe), and $200 \mu$ l for i.p. exposure. Inocula contained from 15 to 25 c.f.u., as determined by plating bacteria onto Middlebrook 7H10 agar medium after each exposure. I.n.exposed mice were sedated by i.p. administration of $10 \mu \mathrm{lg}^{-1}$ of a solution containing $5 \mathrm{mg}$ ketamin $\mathrm{ml}^{-1}$ and $0.3 \mathrm{mg}$ xilazin $\mathrm{ml}^{-1}$. The exposure dose was chosen on the basis of preliminary experiments showing a low level of infection in organs following administration of this dose (data not shown). At various times mice were killed by cervical dislocation and the spleen, lungs and lymph nodes (pools of four axillary and two cervical superficial lymph nodes) were aseptically collected and ground in homogenizers in Middlebrook 7H9 medium (Difco) (6 ml final volume). Two $0.5 \mathrm{ml}$ aliquots of each suspension, either undiluted or diluted tenfold with distilled water containing $0.05 \%$ Tween 80 , were plated onto Middlebrook 7H10 agar medium; the theoretical detection limit of the method was 6 c.f.u. and represented 1 c.f.u. in the homogenate. After incubation for $10-14$ days at $37^{\circ} \mathrm{C}$ in a humidified $5 \% \mathrm{CO}_{2}$ atmosphere, colonies were counted and numbers of c.f.u. per organ, or per pool of lymph nodes, were determined. The experiments with mice were approved by the appropriate authority of the Istituto Superiore di Sanita, Rome.

On day 60, both low-dose-exposed and non-exposed control mice were i.p.-infected with a high-dose bacterial load $\left(10^{5}\right.$ c.f.u.). On days 61, 90, 120 and 150, mice were killed and the spleen, lungs and lymph nodes were collected and processed for c.f.u. counts as described above.
Proliferation assay. Proliferative activity was determined by the tritiated thymidine incorporation assay. Spleen cells were obtained by gentle homogenization of the spleen in RPMI 1640 medium (Life Technologies) containing 10\% heatinactivated $\left(56{ }^{\circ} \mathrm{C}, 30 \mathrm{~min}\right)$ fetal calf serum, $25 \mathrm{mM}$ HEPES and $2 \mathrm{mM}$ L-glutamine (complete RPMI medium). Mononuclear cells were isolated by centrifugation with FicollHypaque (Histopaque 1077, Sigma) and cell viability was determined by the trypan blue dye exclusion method. Cells $\left(2 \times 10^{5}\right.$ per well) were incubated in triplicate wells in humidified $5 \% \mathrm{CO}_{2}$ at $37{ }^{\circ} \mathrm{C}$ with $0,10,20$ or $40 \mu \mathrm{g} \mathrm{ml}{ }^{-1}$ of $M$. avium sonicate in $200 \mu \mathrm{l}$ complete RPMI medium containing $100 \mathrm{U}$ kanamycin $\mathrm{ml}^{-1}, 1 \%$ non-essential amino acids, $1 \mathrm{mM}$ sodium pyruvate for 4 days, or with $1 \mu \mathrm{g} \mathrm{ml} \mathrm{m}^{-1}$ purified phytohaemagglutinin (HA-16; Murex) for 4 days (positive control for cell reactivity). Cells were pulsed with $1.85 \times$ $10^{4} \mathrm{~Bq}$ per well of tritiated thymidine for $8 \mathrm{~h}$. As controls, antigen-free cultures were established. Cells were collected using a cell harvester and the radioactivity (c.p.m.) measured with a beta-scintillation counter. A stimulation index value (c.p.m. with antigen/c.p.m. without antigen) greater than 2 was considered positive for proliferation.

The sonicate was prepared by lysing M. avium cells grown in Middlebrook $7 \mathrm{H} 9$ to the late stationary phase. Ultrasonication was performed at $4{ }^{\circ} \mathrm{C}$ with a VCX $400 \mathrm{~W}$ ultrasonic disintegrator (Sonics \& Materials) for $20 \mathrm{~min}$ (1 min cycles with 1 min cooling intervals); after centrifugation, the protein content in the supernatant was determined by the Bradford assay (Bio-Rad).

Flow cytometry. Spleen and lymph node cells were obtained by gentle homogenization of the tissues in complete RPMI medium. Mononuclear cells were isolated by centrifugation with Ficoll-Hypaque and stained with mouse anti-CD4 (clone RM4-5) monoclonal antibody (Pharmingen). Cells were incubated on ice for $30 \mathrm{~min}$ with appropriate dilutions of the monoclonal antibodies and then washed three times with PBS containing $1 \%$ fetal calf serum and $0.2 \%$ sodium azide. After staining, cells were fixed with $2 \%$ formaldehyde and analysed in a FACScan apparatus (Becton Dickinson) using CellQuest software.

Cytokine determination. Mice were killed and the spleens and lungs aseptically removed. Spleen cells were obtained by gentle homogenization of the spleens in complete RPMI medium. Lungs were thinly sliced with scissors and incubated for $60 \mathrm{~min}$ in agitation at $37^{\circ} \mathrm{C}$ in $5 \mathrm{ml}$ complete RPMI medium containing $40 \mathrm{U}$ collagenase $\mathrm{D} \mathrm{ml}^{-1}$ (Boehringer). The digested tissue was sequentially passed through a nylon sieve and a $21 \mathrm{G}$ needle and then washed with complete RPMI medium. Mononuclear spleen and lung cells were isolated by centrifugation with Ficoll-Hypaque. Cells were washed and resuspended in complete RPMI medium containing $100 \mathrm{U}$ penicillin $\mathrm{ml}^{-1}$ and $100 \mu \mathrm{g}$ streptomycin $\mathrm{ml}^{-1}$ and incubated (in 24-well plates at $3 \times 10^{6}$ spleen cells $\mathrm{ml}^{-1}$ and at $1 \times 10^{6}$ lung cells $\mathrm{ml}^{-1}$, respectively) with or without $20 \mu \mathrm{g}$ M. avium sonicate $\mathrm{ml}^{-\mathbf{1}}$. After $48 \mathrm{~h}$, the cells were centrifuged and the supernatants tested for IL-4, IL-12 p70 and IFN- $\gamma$ concentration by ELISA kits (Quantikine; R\&D Systems).

Determination of anti-M. avium antibodies. Blood was drawn from the retro-orbital sinus of the mice and sera were harvested and examined for anti-M. avium IgG antibodies by an ELISA. Ninety-six-well microtitre plates (Dynatek) were coated overnight at $4{ }^{\circ} \mathrm{C}$ with $1.5 \mu \mathrm{g} \mathrm{ml}^{-1}$ of $M$. avium sonicate (protein content) in $100 \mu \mathrm{l}$ carbonate buffer per well. Plates were washed in PBS containing $0.05 \%$ Tween 20, and twofold serum dilutions in PBS containing 1\% BSA and 0.05\% Tween 
20 (assay diluent) were added. After overnight incubation at $4{ }^{\circ} \mathrm{C}$, biotinylated anti-mouse $\operatorname{IgG} 1$ or $\operatorname{IgG} 2$ a monoclonal antibody (PharMingen) diluted 1:1000 in assay diluent was added and the plates were incubated for $1 \mathrm{~h}$ at $37^{\circ} \mathrm{C}$. After washing, horseradish-peroxidase-conjugated streptavidin dissolved in assay diluent $(1: 2000)$ was added for $1 \mathrm{~h}$ at $37^{\circ} \mathrm{C}$. After washing and incubating in the presence of $o$-phenylenediamine, the $A_{490}$ was read with a microtitre reader (Victor1420 Multilabel Counter; Wallac-Perkin Elmer). End-point titres were expressed as the reciprocal $\log _{2}$ of the last dilution giving an absorbance higher than the cut-off, which was considered twice the background.

Reconstitution of $\mathrm{BALB} / \mathrm{c}$ nude mice with $\mathrm{CD}^{+}{ }^{+} \mathrm{T}$ cell subpopulations. Spleen cells were collected on day 90 from i.n. low-dose-exposed BALB/c mice, or from unexposed mice, and used as a source of primed or unprimed $\mathrm{CD}^{+} \mathrm{T}$ cells, respectively, for reconstitution of athymic BALB/c nude recipient mice. Single-cell suspensions were prepared from $\mathrm{BALB} / \mathrm{c}$ mice spleens in cold PBS supplemented with $0.5 \%$ BSA. CD $4^{+} \mathrm{T}$ cells were purified by positive selection using mouse anti-CD4 MicroBeads (L3T4) and $\mathrm{MS}^{+} / \mathrm{RS}^{+}$columns (Miltenyi Biotec). This procedure resulted in $\geqslant 98 \% \mathrm{CD}^{+}$ $T$ cells as assessed by flow cytometry. BALB/c nude mice were injected through the tail vein $\left(3 \times 10^{6} \mathrm{CD}^{+} \mathrm{T}\right.$ cells per mouse $)$ and after 1 day were infected i.p. with $10^{5}$ M. avium c.f.u. Unreconstituted nude mice were infected in parallel and used as controls. At 30 days after the infection, both unreconstituted and reconstituted mice were killed and their spleens were collected and processed for c.f.u. counts.

Statistical analysis. Statistical significance of the data was determined by the two-tail Student's $t$-test, unless otherwise indicated; $P<0.05$ was considered significant. Results are expressed as means $\pm \mathrm{SD}$.

\section{RESULTS}

\section{Exposure to low doses of $M$. avium increases resistance against a subsequent high-dose infection in immunocompetent BALB/c mice}

BALB/c mice exposed to 20 M. avium c.f.u. administered i.n., i.p. or i.d. at three different times 2 weeks apart developed chronic infections in the spleen, lungs and lymph nodes which persisted for more than 150 days (Fig. 1). The i.n. route was less invasive than the other two routes, with c.f.u. values not exceeding 50 in the spleen and lungs on days 60 and 150 , and 100 c.f.u. in the lymph nodes on day 150. Mice exposed i.p. showed a more consistent disease in the spleen ( $\leqslant 6000$ c.f.u.) and lungs ( $\leqslant 250$ c.f.u.) throughout the whole period of observation, and 100 c.f.u. in the lymph nodes on day 150. Intermediate (between 30 and 1100 c.f.u.) values were found in the lungs and spleen of mice exposed i.d. in the epidermis of the sternal region to low doses of $M$. avium; in contrast, these mice had a high mycobacterial load in their lymph nodes ( $>10^{5}$ c.f.u. on day 150$)$.

When mice exposed to low doses of $M$. avium were infected i.p. with $10^{5}$ c.f.u. on day 60 (Fig. 1), no differences between the c.f.u. numbers of the challenged low-dose-exposed mice and control mice were found on day 61, with the exception of the lymph nodes of i.d.exposed mice, in which the c.f.u. numbers were higher than in control mice. The second infection was significantly limited in the spleen on days 90, 120 and 150 as compared to unexposed control mice. A lower but significant containment of the infection was also observed in the lungs and lymph nodes, especially in lowdose i.p.-exposed mice. Following high-dose infection, the bacterial load in the lymph nodes of low-dose i.d.exposed animals was higher than in unexposed mice.

To ascertain whether the control of the second infection was dependent on the recruitment of a specific immune response, we repeated the experiments in congenitally athymic BALB/c nude mice. As shown in Fig. 2, $M$. avium progressively grew in the tissues of these mice exposed to i.p. or i.d. inoculation of 20 c.f.u.; after an initial delay, a high growth rate was observed in nude i.n.-exposed mice. No animal deaths were recorded during the whole experimental period. Following challenge, no c.f.u. differences were found on day 61 between i.n.-low-dose-exposed and control mice; however, in the challenged i.p.- and i.d.-low-dose-exposed mice the c.f.u. numbers were higher than in the controls because of the pre-existent infection. Due to immune deficiency of these mice, no c.f.u. differences were usually observed in time between the challenged low-dose exposed mice and controls. However, on day 150 a higher c.f.u. difference (not statistically significant) was seen between the challenged low-dose exposed mice and controls in the spleen and lymph nodes of i.n.-low-dose-exposed mice and in the spleen and lungs of i.p.-low-doseexposed mice. Seventeen per cent of challenged i.d.- or i.p.-low-dose-exposed mice ( 2 out of 12 per group) died between day 120 and day 150 .

\section{Exposure to low doses of $M$. avium induces an immune response in BALB/c mice}

To study the immune response generated by exposure to low doses of M. avium, cell proliferation, expression of mononuclear cell surface markers, cytokine production and serum antibodies were examined.

Thirty-three per cent of mice exposed i.d. or i.p. to low doses of $M$. avium responded to $M$. avium antigens on days 60 (stimulation indexes of $2 \cdot 2$ and $2 \cdot 3$ for i.d.- and i.p.-exposed mice, respectively) and 150 (stimulation index of 3.2 for i.p.-exposed mice); in contrast, no cell proliferation was observed in the spleen cells either of i.n.-exposed mice or of control mice (data not shown).

The number of $\mathrm{CD}^{+} \mathrm{T}$ cells in animals exposed to low doses of $M$. avium was evaluated on day 60 by flow cytometry analysis of spleen and lymph node cells (Fig. 3). A significant increase in $\mathrm{CD}^{+}{ }^{+} \mathrm{T}$ cells was observed in the spleen of all low-dose-exposed mice; a similar trend was seen in the lymph nodes, although only cells of i.n.- and i.p.-exposed mice showed a significant increase in this tissue.

The amount of IL-12, IFN- $\gamma$ and IL-4 in the supernatants of spleen and lung cells collected from low-dose-exposed and unexposed control mice stimulated in vitro with $M$. 

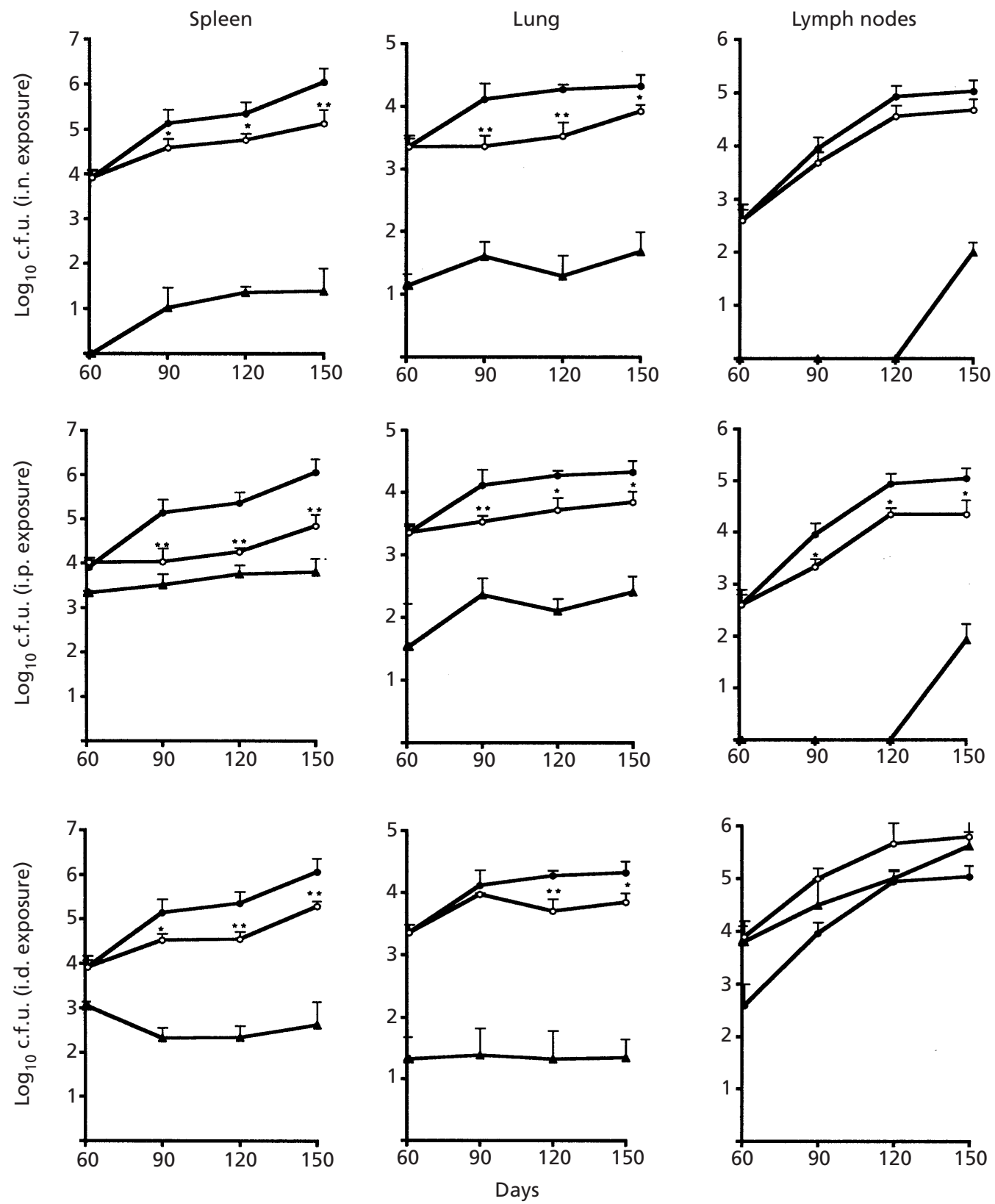

Fig. 1. BALB/c mice were exposed i.n. (top), i.p. (middle) or i.d. (bottom) to 20 c.f.u. at three different times 2 weeks apart (days 0,14 and 28), and c.f.u. were determined in the spleen, lungs and lymph nodes on days 60, 90,120 and 150 ( $\boldsymbol{\Delta}$ ). Mice exposed i.n., i.d. or i.p. to 20 c.f.u. (○), and unexposed control mice (0), were challenged i.p. with $10^{5}$ c.f.u. on day 60 , and c.f.u. were determined on days 61,90, 120 and 150. Data represent the mean of two experiments $(n=8-12$ mice per time point per group in each experiment). Error bars represent SD. Values below the theoretical detection limit of the method (6 c.f.u.) are reported as 0 c.f.u. per organ or per pool of lymph nodes. A statistically significant decrease in log 10 c.f.u. compared to control mice is indicated with one asterisk for $P<0.05$, or two asterisks for $P<0.01$.

avium antigens is shown in Fig. 4. When spleen cells (a) or lung cells (b) were cultured with M. avium sonicate, IL-12 was mainly produced on day 60 in all low-doseexposed mice, in comparison with control mice, and decreased on day 150 . In contrast, IFN- $\gamma$ production increased between day 60 and day 150, with the i.n. and i.p. routes inducing more abundant cytokine levels than the i.d. route. With respect to IL-4, no induction was observed in spleen and lung cells of i.n.- and i.d.- exposed mice, while an appreciable amount of this cytokine was observed on day 60 and day 150, especially in the lung cells of i.p.-exposed mice.

Appreciable antibody titres against $M$. avium antigens were present only in the serum of mice exposed to 20 c.f.u. by the i.d. route, with reciprocal $\log _{2} \operatorname{IgG} 2 \mathrm{a}$ and IgG1 titres being $13 \cdot 64 \pm 1$ and $13 \cdot 64 \pm 1$ on day 60 , respectively, and $5 \cdot 64 \pm 0$ and $7 \cdot 64 \pm 2$ on day 150 , 

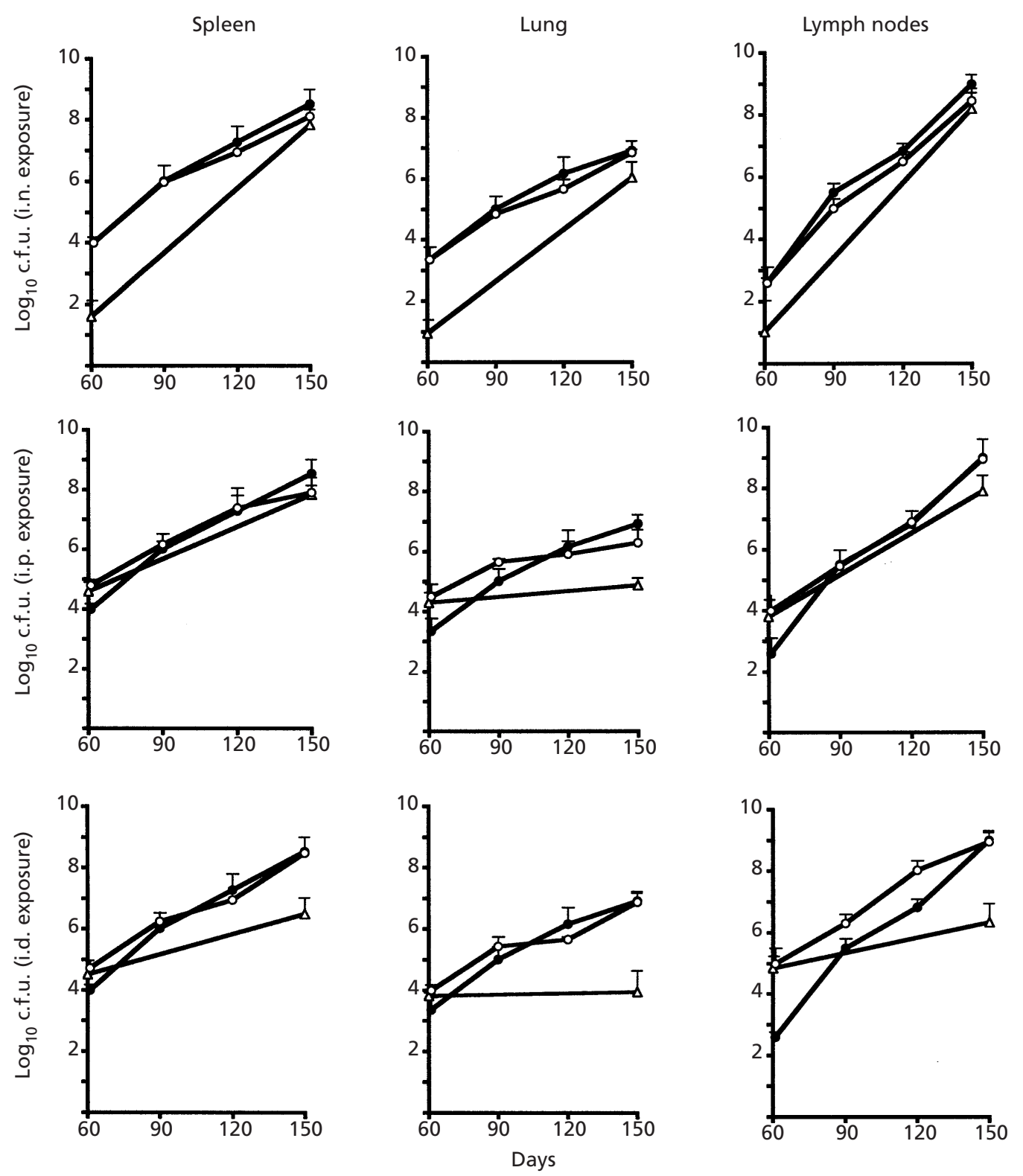

Fig. 2. BALB/c nude mice were exposed i.n. (top), i.p. (middle) or i.d. (bottom) to 20 c.f.u. at three different times 2 weeks apart (days 0, 14 and 28), and c.f.u. were determined in the spleen, lungs and lymph nodes on days 60 and 150 ( $\triangle$ ). Mice exposed i.n., i.d. or i.p. to 20 c.f.u. (O), and unexposed control mice (O), were challenged i.p. with $10^{5}$ c.f.u. on day 60 , and c.f.u. were determined on days 61,90, 120 and 150. Data represent the mean of two experiments $(n=6$ mice per time point per group in each experiment). Error bars represent SD.

respectively. No IgG2a and IgG1 serum antibodies were detected in i.n.- or i.p.-exposed mice, or control mice.

\section{BALB/c nude mice are protected against $M$. avium high-dose infection following transfer of CD4 ${ }^{+}$ $T$ cells from low-dose i.n.-exposed BALB/c mice}

I.n.-exposed BALB/c mice showed the lowest mycobacterial load in organs and developed a protective state against high-dose infection, coincident with expansion of $\mathrm{CD}^{+}{ }^{+} \mathrm{T}$ cells and a high IFN- $\gamma / \mathrm{IL}-4$ ratio (see above). We therefore attempted to define a possible role of $\mathrm{CD} 4^{+}$
$\mathrm{T}$ cells in the resistance acquired following i.n. exposure to low $M$. avium doses. With this aim, naive BALB/c nude mice were reconstituted with unprimed BALB/c mice $\mathrm{CD}^{+} \mathrm{T}$ cells or with $M$. avium-primed $\mathrm{CD}^{+} \mathrm{T}$ cells isolated on day 90 from BALB/c mice exposed i.n. to 20 c.f.u. as shown in Fig. 1. Both reconstituted and unreconstituted (control) mice were challenged i.p. with $10^{5}$ c.f.u. the following day. Thirty days after infection, c.f.u. values in the spleen ( 5 mice per group) were as follows: control, $5 \cdot 63 \pm 0 \cdot 38 \log _{10}$ c.f.u.; mice reconstituted with unprimed $\mathrm{BALB} / \mathrm{c}$ mice $\mathrm{CD}^{+} \mathrm{T}$ cells, $5.36 \pm 0.37 \log _{10}$ c.f.u.; mice reconstituted with i.n.- 


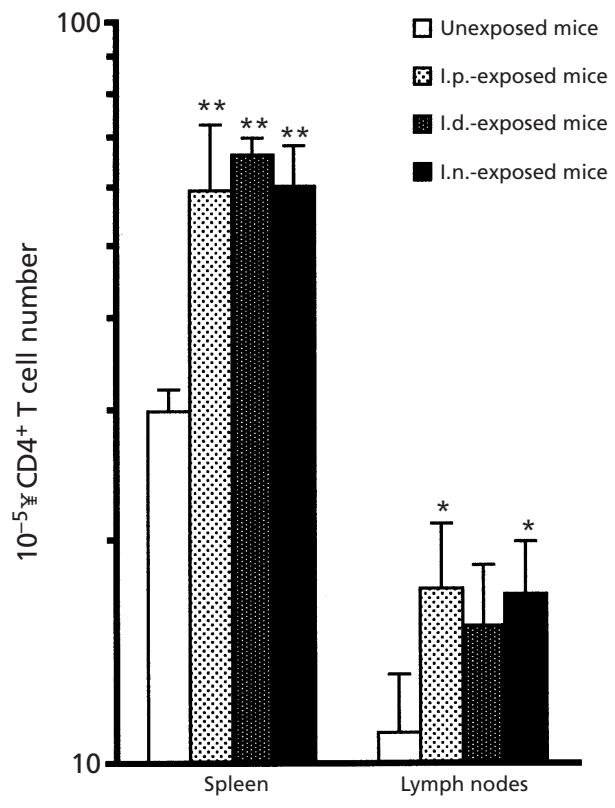

Fig. 3. Flow cytometric analysis of spleen and lymph node cells of BALB/C mice exposed to 20 c.f.u. as in Fig. 1. Cells were collected on day 60 and stained with anti-CD4 ${ }^{+} \mathrm{T}$ cells monoclonal antibodies. Data shown represent the mean of two experiments ( $n=3$ mice per group in each experiment). Error bars represent SD. A statistically significant increase in the number of $\mathrm{CD}^{+} \mathrm{T}$ cells compared to control mice is indicated with one asterisk for $P<0.05$, or two asterisks for $P<0.01$.

primed BALB/c mice CD4 $4^{+} \mathrm{T}$ cells, $4 \cdot 88 \pm 0 \cdot 42 \log _{10}$ c.f.u. $(P=0.008$ in comparison with control, and $P=$ $0 \cdot 042$, one-tail Student's $t$-test, in comparison with mice reconstituted with unprimed $\mathrm{CD} 4{ }^{+} \mathrm{T}$ cells).

\section{DISCUSSION}

Exposure to a few M. avium bacteria is a common event, whereby the host continuously interacts with these organisms in the environment (von Reyn et al., 1993; Falkinam, 1996; Horshburgh, 1996; Falkinam et al., 2001). In spite of this, not much is known about the host-parasite relationship following low-dose infections. As M. avium organisms usually infect the human host through the respiratory or gastrointestinal tract (Inderlied et al., 1993), the nasal mucosa is a probable entry point. It is known that $M$. avium adheres to fibrous mucus and to the damaged mucosa of the turbinate tissue (Middleton et al., 2000). On the other hand, small numbers of $M$. avium bacteria may penetrate through parenteral routes, including both the i.d. route, following traumatic inoculation through the skin (Smith \& Grange, 1989; Noguchi et al., 1998), and the i.p. route, as occurs in patients undergoing continuous ambulatory peritoneal dialysis (Hakim et al., 1993; Perlino et al., 1993).

In our model, when BALB/c mice were exposed i.n. to low doses of $M$. avium to mimic environmental conditions, the few organisms that were initially found in the lungs (day 60) later disseminated to the spleen and cervical and/or axillary lymph nodes (day 150). The late recovery of mycobacteria in the lymph nodes indicates that host defences are unable to prevent the escape of bacteria from chronically infected tissues. More consistent infections were observed when 20 c.f.u. were given parenterally (i.d. and i.p.), with a particular tendency of i.d.-exposed mice to permit an efficient growth of the mycobacteria in the lymph nodes. The latter occurrence may be due to the fact that the i.d. exposure to $M$. avium was performed through the sternal region, which should drain cervical and/or axillary lymph nodes.

In nude mice, which are $\mathrm{BALB} / \mathrm{c}$ mice devoid of a functional thymus and hence deficient in TCR $\alpha \beta^{+} \mathrm{T}$ cells (Pantelouris, 1968; Emoto et al., 1997), low-dose exposure was followed by efficient growth of M. avium in the whole body, indicating that TCR $\alpha \beta^{+} \mathrm{T}$ cells play an essential role in the control of infection with few organisms. These observations are in accordance with reports indicating that severely $\mathrm{T}$-cell-deficient persons such as AIDS patients are at high risk of infection with low-dose-containing sources like water aerosols (Falkinam, 1996; Falkinam et al., 2001; Horshburgh, 1996). Mycobacteria enter the host also by the i.d. route through cuts and skin punctures (Smith \& Grange, 1989). Our data show that i.d. exposure to a few organisms results in infection of cervical and/or axillary lymph nodes in both BALB/c and nude mice, suggesting that skin lesions may also be responsible for the cervical lymphadenitis seen in humans (Smith \& Grange, 1989).

In order to study the mechanisms activated by exposure to low doses of $M$. avium, the antigen-specific immune response was investigated. When a proliferative test was performed, the spleen cells of mice exposed i.d. or i.p., but not i.n., to low doses of $M$. avium, responded to mycobacterial antigens. The lack of response observed in i.n.-exposed mice may be due either to low frequency or to body compartmentalization of specific memory cells. By cytofluorimetric analysis, all low-dose-exposed mice showed an increase in the number of $\mathrm{CD}^{+} \mathrm{T}$ cells, indicating that this population was expanded in response to $M$. avium antigens even when few bacteria were present in the tissues, as observed in i.n.-exposed mice. As previously established, $\mathrm{CD}^{+} \mathrm{T}$ cells play an essential role in effectively defending the host against $M$. avium and their depletion is responsible for M. avium dissemination in HIV-infected patients (Inderlied et al., 1993). Several studies have previously confirmed the protective anti- $M$. avium role of $\mathrm{CD} 4^{+} \mathrm{T}$ cells, but not $\mathrm{CD} 8^{+} \mathrm{T}$ cells, in mice, although these investigations were usually conducted using $\geqslant 10^{5}$ c.f.u. (Appelberg et al., 1995; Saunders \& Cheers, 1995 ; Nagabhushanam \& Cheers, 2001); in contrast, no studies have been performed with small numbers of bacteria inoculated through routes more similar to those occurring under environmental or traumatic conditions.

Interestingly, while BALB/c mice with an ongoing infection due to low doses of $M$. avium had increased 

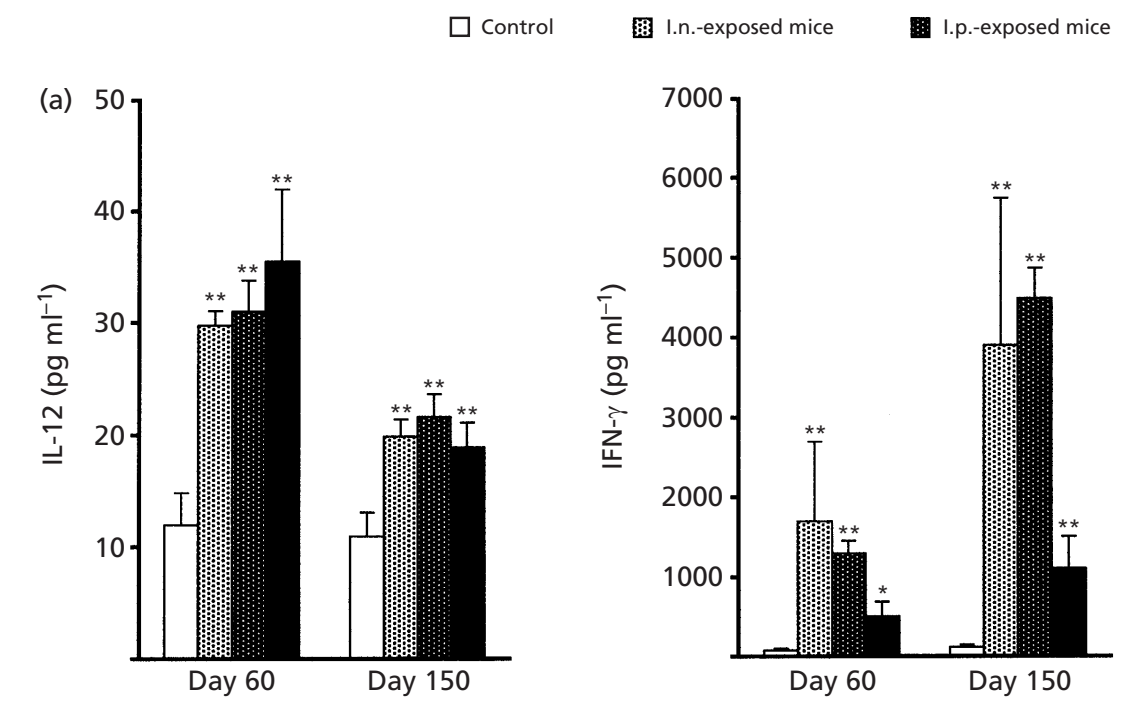

I.d.-exposed mice
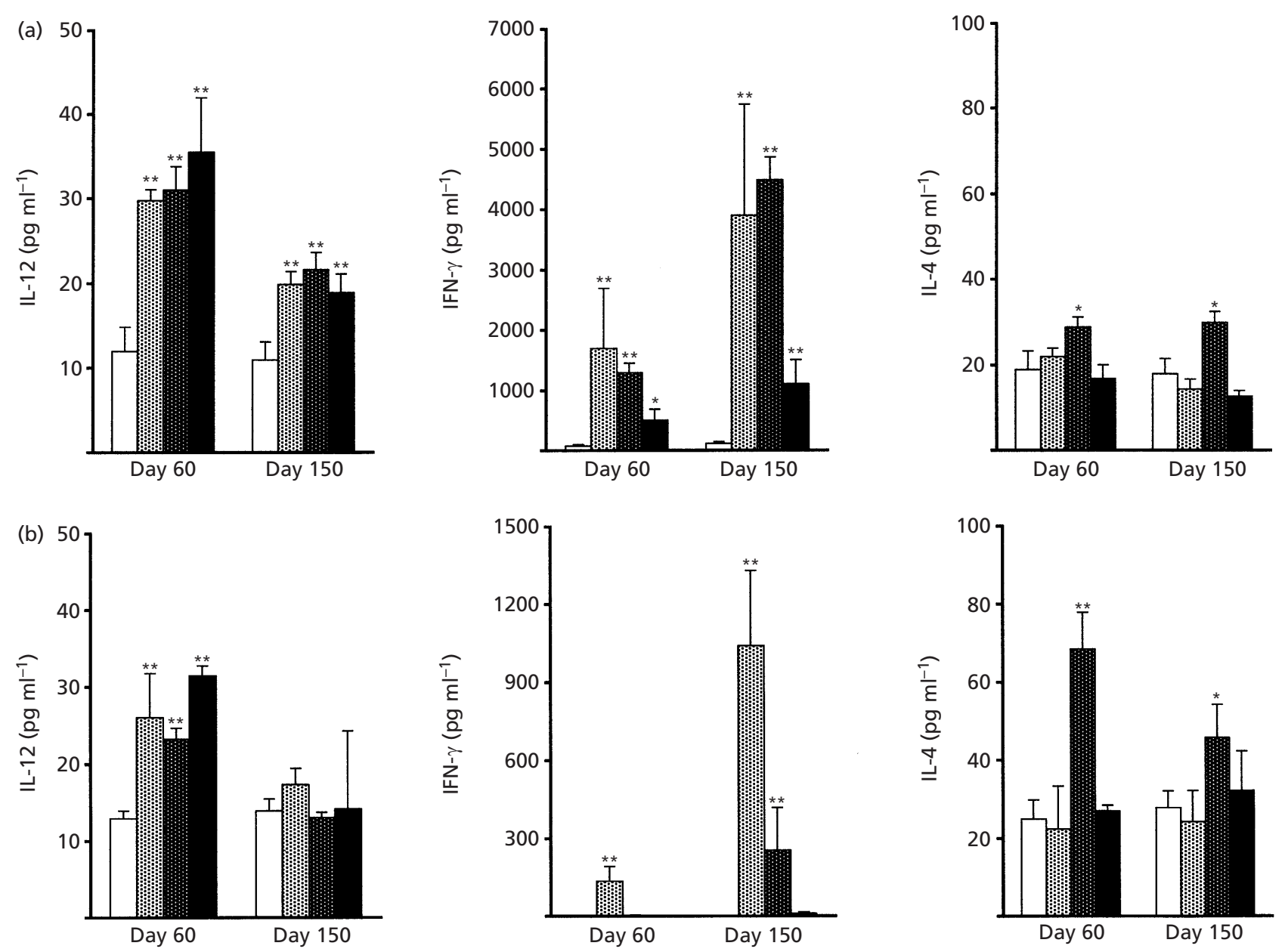

Fig. 4. Release of IL-12 p70 (left), IFN- $\gamma$ (middle) and IL-4 (right) in the supernatants of spleen cells (a) and lung cells (b) of BALB/c mice after stimulation with $20 \mu \mathrm{g}$ M. avium sonicate $\mathrm{ml}^{-1}$ for $48 \mathrm{~h}$. Mice were either unexposed, or exposed i.n., i.p. or i.d. to 20 c.f.u. as in Fig. 1. Data shown represent the mean of two experiments ( $n=3$ mice per time point per group in each experiment). Error bars represent SD. A statistically significant increase in cytokine release compared to control mice is indicated with one asterisk for $P<0.05$, or two asterisks for $P<0.01$.

resistance to a subsequent high-dose infection, this did not occur in congenitally athymic BALB/c nude mice. This suggests that the priming with low mycobacterial doses for protection against a further infection was related to elicitation of immune responses mediated by T lymphocytes with the $\alpha \beta \mathrm{T}$ cell receptor. The small resistance developed in some organs of nude mice on day 150 may be related to thymus-independent development of TCR $\alpha \beta^{+}$T cells, which are known to be expressed with age in these animals (Emoto et al., 1997).

To demonstrate the role of the cellular immune response in the protection against high-dose infection, we isolated $\mathrm{CD}^{+}{ }^{+} \mathrm{T}$ cells from i.n.-primed BALB/c mice and used them to reconstitute naive nude mice. Following reconstitution, nude mice were protected against high-dose infection by $M$. avium-primed $\mathrm{CD}^{+}{ }^{+} \mathrm{T}$ cells. The slight protection induced by unprimed $\mathrm{CD} 4^{+} \mathrm{T}$ cells may be in part explained by the possibility that $\mathrm{T}$ cells from naive mice can recognize microbial antigens that cross-react with, or are common to, M. avium antigens. Thus, our observations indicate that i.n. exposure to low doses induces protective $\mathrm{CD}^{+} \mathrm{T}$ cells in normal hosts, supporting the knowledge that in severely CD4-deficient persons, such as AIDS patients, a M. avium respiratory infection originating from environmental sources is predictive of mycobacterial dissemination (Chin et al., 1994; Inderlied et al., 1993).

Regardless of the route used, low-dose exposures were associated with production of IL-12 at a time (day 60) when infection in the organs was already established. Since IL-12 primes CD4 ${ }^{+} \mathrm{T}$ cells for IFN- $\gamma$ production and protective immunity in mice infected with high doses of M. avium (Silva et al., 2001), it may also be important for the development of resistance to a subsequent high-dose infection in low-dose-exposed mice. The release of IL-12 coincided with or immediately 
preceded that of IFN- $\gamma$; however, it was surprising to find that weakly burdened i.n.-exposed mice triggered IFN- $\gamma$ at levels equal to or even higher than those in animals harbouring $10^{4}$ c.f.u. per organ, such as i.p.exposed mice. Given the strict requirement for IFN- $\gamma$ and $\mathrm{CD}^{+} \mathrm{T}$ cells in the development of protective immunity to high doses of $M$. avium, the minimal mycobacterial load in the tissue and long-lasting resistance by i.n.-exposed mice may be due to a concomitant increase in the number of $\mathrm{CD}^{+} \mathrm{T}$ cells and production of high levels of IFN- $\gamma$ and IL-12.

The parenterally (i.p.- and i.d.)-exposed mice showed mycobacterial loads higher than i.n.-exposed mice and were characterized by a mixed Th1/Th2 response with production of IFN- $\gamma$ and IL-4 in the case of i.p.-infected mice, and of IFN- $\gamma$ and IgG1 and IgG2a antibodies in the case of i.d.-exposed mice. This is in keeping with the knowledge that BALB/c mice infected with high doses of $M$. avium produce IL-4, IFN- $\gamma$ and a mixture of IgG1 and IgG2a (Nagabhushanam \& Cheers, 2001).

In previous studies with low doses of Candida albicans (Mencacci et al., 1996) and BCG (Power et al., 1998), the existence of a threshold dose of an infectious agent determining whether Th1 or Th2 responses are generated was assumed (Power et al., 1998; Menon et al., 1998; Bretscher et al., 2001). A close comparison of our results with the study of Power et al. (1998) is not possible for various reasons, including differences in the mycobacterial species, pathogenicity and doses, and, more importantly, the fact that we used different exposure routes. Nonetheless, our results for the i.d. antibody production are in keeping with their observations. In addition we found that, differently from the events resulting from i.p. or i.d. exposure, repeated i.n. exposure to 20 c.f.u. - as is likely to occur in the environment - induces a Th1 imprint on the immune system associated with $\mathrm{CD} 4^{+} \mathrm{T}$-cell-mediated, acquired resistance against further infections.

\section{ACKNOWLEDGEMENTS}

We would like to thank Professor Antonio Cassone, Istituto Superiore di Sanita, Rome, Italy, for his help in reviewing the manuscript. We also thank Lara Brunori, Istituto Superiore di Sanita, for technical assistance. This work was supported in part by the Italian AIDS Project, Istituto Superiore di Sanita, Ministero della Sanità, Grants 50D.5 and 50D.4.

\section{REFERENCES}

Appelberg, R., Castro, A. G., Pedrosa, J., Silva, R. A., Orme, J. M. \& Minoprio, P. (1995). Role of gamma interferon and tumor necrosis factor alpha during T-cell-independent and -dependent phases of Mycobacterium avium infection. Infect Immun 62, 3962-3971.

Bretscher, P., Menon, J., Power, C., Uzonna, J. \& Wei, G. (2001). A case for a neonatal, low-dose BCG vaccination trial. Scand J Infect Dis 33, 253-257.

Brown, D. H., Miles, B. A. \& Zwilling, B. S. (1995). Growth of Mycobacterium tuberculosis in BCG-resistant and -susceptible mice: establishment of latency and reactivation. Infect Immun $\mathbf{6 3}$, 2243-2247.

Chambers, M. A., Williams, A., Gavier-Widen, D., Whelan, A., Hughes, C., Hall, G., Lever, M. S., Marsh, P. D. \& Hewinson, R. G. (2001). A guinea pig model of low-dose Mycobacterium bovis aerogenic infection. Vet Microbiol 80, 213-226.

Chin, D. P., Hopewell, P. C., Yajko, D. M. \& 9 other authors (1994). Mycobacterium avium complex in the respiratory or gastrointestinal tract and the risk of $M$. avium complex bacteremia in patients with human immunodeficiency virus infection. J Infect Dis 169, 289-295.

Cooper, A. M., Callahan, J. E., Griffin, J. P., Roberts, A. D. \& Orme, I. M. (1995). Old mice are able to control low-dose aerogenic infections with Mycobacterium tuberculosis. Infect Immun 63, 3259-3265.

Corti, A., Fattorini, L., Thoresen, O. F., Ricci, M. L., Gallizia, A., Pelagi, M., Li, Y. \& Orefici, G. (1999). Upregulation of p75 tumor necrosis factor alpha receptor in Mycobacterium avium-infected mice: evidence for a functional role. Infect Immun 11, 5762-5767.

Eaton, T., Falkinham, J. O., III \& von Reyn, C. F. (1995). Recovery of Mycobacterium avium from cigarettes. J Clin Microbiol 33, 2757-2758.

Emoto, M., Emoto, Y. \& Kaufmann, S. H. (1997). CD $8 \alpha \beta^{+}$TCR $\alpha \beta^{\text {intermediate }}$ lymphocytes expressing skewed TCRV $\beta$ repertoire in the liver of aged athymic nu/nu mice. J Immunol 158, 1041-1050.

Falkinham, J. O., III (1996). Epidemiology of infection by nontuberculous mycobacteria. Clin Microbiol Rev 9, 177-215.

Falkinham, J. O., III, Norton, C. D. \& LeChevallier, M. W. (2001). Factors influencing numbers of Mycobacterium avium, Mycobacterium intracellulare, and other mycobacteria in drinking water distribution systems. Appl Environ Microbiol 67, 1225-1231.

Fattorini, L., Xiao, Y., Ausiello, C. M., Urbani, F., LaSala, A., Mattei, M. \& Orefici, G. (1996). Late acquisition of hyporesponsiveness to Mycobacterium avium-infected human macrophages in producing tumor necrosis factor- $\alpha$ but not interleukin- $1 \beta$ and -6. J Infect Dis 173, 1030-1033.

Hakim, A., Hisam, N. \& Reuman, P. D. (1993). Environmental mycobacterial peritonitis complicating peritoneal dialysis: three cases and review. Clin Infect Dis 16, 426-431.

Horshburgh, C. R., Jr (1996). Epidemiology of Mycobacterium avium complex. In Mycobacterium avium Complex Infection. Progress in Research and Treatment, pp. 1-22. Edited by J. A. Korvick \& C. A. Benson. New York: Marcel Dekker.

Inderlied, C. B., Kemper, C. A. \& Bermudez, L. E. M. (1993). The Mycobacterium avium complex. Clin Microbiol Rev 6, 266-310.

Kobayashi, K., Kasama, T., Yamazaki, J., Hosaka, M., Katsura, T., Mochizuki, T., Soejima, K. \& Nakamura, R. M. (1995). Protection of mice from Mycobacterium avium infection by recombinant interleukin-12. Antimicrob Agents Chemother 39, 1369-1371.

Mencacci, A., Spaccapelo, R., Del Sero, G., Enssle, K. H., Cassone, A., Bistoni, F. \& Romani, L. (1996). CD4 ${ }^{+}$T-helper-cell responses in mice with low-level Candida albicans infection. Infect Immun 64, 4907-4914.

Menon, J. N. \& Bretscher, P. A. (1998). Parasite dose determines the Th1/Th2 nature of the response to Leishmania major independently of infection route and strain of host or parasite. Eur J Immunol 28, 4020-4028.

Middleton, A. M., Chadwick, M. V., Nicholson, A. G., Dewar, A., Groger, R. K., Brown, E. J. \& Wilson, R. (2000). The role of Mycobacterium avium complex fibronectin attachment protein in adherence to the human respiratory mucosa. Mol Microbiol 38, 381-391. 
Nagabhushanam, V. \& Cheers, C. (2001). Non-major histocompatibility complex control of antibody isotype and Th1 versus Th2 cytokines during experimental infection of mice with Mycobacterium avium. Infect Immun 69, 1708-1713.

Noguchi, H., Hiruma, M., Kawada, A., Fujimoto, N., Fujioka, A. \& Ishibashi, A. (1998). A pediatric case of atypical Mycobacterium avium infection of the skin. J Dermatol 25, 384-390.

Pantelouris, E. M. (1968). Absence of thymus in a mouse mutant. Nature 27, 370.

Perlino, C. A. (1993). Mycobacterium avium complex: an unusual cause of peritonitis in patients undergoing continuous ambulatory peritoneal dialysis. Clin Infect Dis 17, 1083-1084.

Power, C. A., Wei, G. \& Bretscher, P. A. (1998). Mycobacterial dose defines the Th1/Th2 nature of the immune response independently of whether immunization is administered by the intravenous, subcutaneous, or intradermal route. Infect Immun 66, 5743-5750.

Saunders, B. M. \& Cheers, C. (1995). Inflammatory response following intranasal infection with Mycobacterium avium com- plex: role of T-cell subsets and gamma interferon. Infect Immun 63, 2282-2287.

Saunders, B. M., Frank, A. A., Cooper, A. M. \& Orme, I. M. (1998). Role of $\gamma \delta$ T cells in immunopathology of pulmonary Mycobacterium avium infection in mice. Infect Immun 66, 5508-5514.

Silva, R. A., Florido, M. \& Appelberg, R. (2001). Interleukin-12 primes $\mathrm{CD}^{+} \mathrm{T}$ cells for interferon- $\gamma$ production and protective immunity during Mycobacterium avium infection. Immunology 103, 368-374.

Smith, M. J. \& Grange, J. M. (1989). Deep tissue infections due to environmental mycobacteria. In The Biology of the Mycobacteria, vol. 3, pp. 511-564. Edited by C. Ratledge, J. Stanford \& J. M. Grange. New York: Academic Press.

von Reyn, C. F., Waddel, R. D., Eaton, T. \& 10 other authors (1993). Isolation of Mycobacterium avium complex from water in the United States, Finland, Zaire, and Kenya. J Clin Microbiol 31, 3227-3230.

Received 12 March 2002; revised 16 April 2002; accepted 20 May 2002. 